\title{
Essential oil from leaves of Lantana camara: a potential source of medicine against leishmaniasis
}

\author{
Rachel R. P. Machado, ${ }^{* 1}$ Wilson Valente Júnior, ${ }^{2}$ Bernhard \\ Lesche, ${ }^{3}$ Elaine S. Coimbra, ${ }^{2}$ Nicolli B. de Souza, ${ }^{2}$ Clarice \\ Abramo, ${ }^{2}$ Geraldo Luiz G. Soares, ${ }^{4}$ Maria Auxiliadora C. \\ Kaplan $^{5}$
}

\author{
${ }^{1}$ Programa de Pós-graduação em Biotecnologia Vegetal, Universidade Federal \\ do Rio de Janeiro, Brazil and Faculdade de Ciências Médicas e da Saúde, \\ Suprema, Brazil, \\ ${ }^{2}$ Laboratório de Parasitologia, Departamento de Parasitologia, Microbiologia \\ e Imunologia, Universidade Federal de Juiz de Fora, Brazil, \\ ${ }^{3}$ Departamento de Física, Instituto de Ciências Exatas, Universidade Federal \\ de Juiz de Fora, Brazil, \\ ${ }^{4}$ Departamento de Botânica, Instituto de Biociências, Universidade Federal do \\ Rio Grande do Sul, Brazil, \\ ${ }^{5}$ Núcleo de Pesquisa de Produtos Naturais, Centro de Ciências da Saúde, \\ Universidade Federal do Rio de Janeiro, Brazil.
}

\begin{abstract}
Leishmaniasis is an infection of viscera or tegument caused by protozoa Leishmania sp. The extensive period required for the treatment, which involves the use of toxic medicines, leads patients to drop treatment increasing the development of resistant forms of Leishmania sp. Lantana camara L., Verbenaceae, is a tropical plant native from America. Folk uses have been described for treatment of tumors, tetanus, rheumatism and malaria. This study evaluates the leishmanicidal activity of the essential oil of leaves from $L$. camara on promastigote forms of Leishmania chagasi and L. amazonensis and its toxic effects on Artemia salina (brine shrimp test), macrophage cultures and BALB/c mice. The chemical composition was evaluated using the gas chromatography coupled with mass spectrometer (GC-MS). Thirty substances, mostly mono and sesquiterpenes were identified. The most representative constituents were: germacrene D $(24.90 \%)$, farnesene derivatives $(22 \%)$ and $(E)$-cariophylene $(14.31 \%)$. Bioassays revealed a significant leishmanicidal activity of essential oil against L. amazonensis (IC50 $0.25 \mu \mathrm{g}$ / $\mathrm{mL}$ ) and a potential toxic effect on Brine shrimp (LC50 $10 \mu \mathrm{g} / \mathrm{mL})$ and macrophage assays (CC50 $4 \mu \mathrm{g} / \mathrm{mL}$ ), while there was no toxic manifestation on mice. The data show the relevant potential of $L$. camara as a source of medicine for leishmaniasis treatment.
\end{abstract}

Revista Brasileira de Farmacognosia Brazilian Journal of Pharmacognosy 22(5): 1011-1017, Sep./Oct. 2012

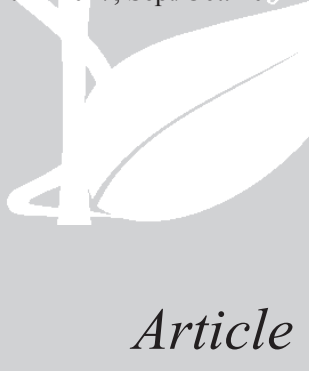

Received 25 Oct 2011

Accepted 22 Mar 2012

Available online 24 Apr 2012

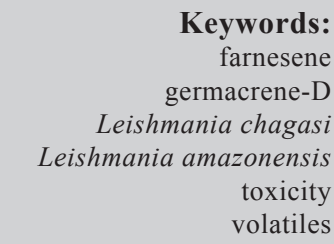

ISSN 0102-695X http://dx.doi.org/10.1590/S0102$695 \times 2012005000057$

\section{Introduction}

Leishmaniasis is endemic in 88 countries of Tropical and Sub-tropical regions, affecting more than 12 million people (WHO, 2010). Protozoan parasites of the Leishmania genus are the causative agents of human leishmaniasis, which has a spectrum of diseases ranging from self-healing ulcers to fatal visceral infection. In Brazil, among the fourteen species of Leishmania identified, ten are known to infect human beings (Cruz et al., 2009). In humans, visceral, cutaneous, and mucosal leishmaniasis result from infection of macrophages throughout the mononuclear-phagocyte system, in the skin, and in the naso-oropharyngeal mucosa, respectively (Murray et al., 2005).
Until now, no vaccines have been available for any form of leishmaniasis, and the chemotherapy is still inadequate since drugs currently used (Amphotericin $\mathrm{B}$, Pentavalent antimony, Pentamidine isethionate, Paramomycin sulfate) exhibits high levels of toxicity (Clem, 2010). In this context, natural substances in particular natural products from plants against leishmaniasis, can be an interesting source of drugs against leishmaniasis (Salem \& Werbovetz, 2006). Numerous studies about the activity of plant extracts against both forms of Leshmania sp., the promastigote form (infecting form) and the amastigote form (pathogenic form), have been performed (Bezerra et al., 2006; Cammerer etal., 2007; Mishra et al., 2007).

Lantana camara L., Verbenaceae, a native species 
of tropical America, was introduced in several countries as a hedge and an ornamental shrub (Raju, 2000). All parts of the plant are known by having toxic characteristics due to the hepatotoxic triterpenes (Sharma et al., 2007). Its toxicity was also showed in ruminant grazing animals (Tokarnia et al., 1999). On the other hand, therapeutics characteristics of this plant should be considered once the population uses it to treat several health disorders as respiratory diseases, rheumatisms, malaria, dysenteries, headache, hypertension and cancer (Ghisalberti, 2000; Deena \& Thoppil, 2000).

The literature has shown that the essential oil from leaves of L. camara (EOLC) was able to play as an anti-inflammatory agent in vivo and has a potential antimicrobial action in vitro (Deena \& Thoppil, 2000). Braga et al. (2007) showed that the methanol extract from leaves of $L$. camara had a potential activity in vitro against promastigote forms of Leishmania amazonensis.

In view of the fact that none evaluation about the potential of the EOLC against Leishmania sp. are known and the compounds that are the major responsible for the high levels of toxicity (triterpenes), are not present in essential oil, the present work aim to evaluate the potential of EOLC against L. amazonensis and L. chagasi. This evaluation is done in vitro with the promastigote form of Leshmania. Further the toxicity of EOLC is evaluated in vitro with brine shrimp and macrophages and in vivo with $\mathrm{BALB} / \mathrm{c}$ mice.

\section{Materials and Methods}

\section{Plant material}

Leaves of Lantana camara L., Verbenaceae, were collected in Juiz de Fora-MG, Brazil, in February 2007. The plant material was identified by Dr. Fátima Regina Gonçalves Salimena (Departamento de Botânica, Universidade Federal de Juiz de Fora), and a voucher specimen (CESJ 46090) was deposited at the Herbarium Leopoldo Krieger (Universidade Federal de Juiz de Fora). Before obtaining the essential oil, air dried leaves were weighted to calculate the yield percentage of essential oil. Essential oil was obtained by means of hydro-distillation using a Clevenger apparatus and a glass balloon of $3 \mathrm{~L}$. The procedure of essential oil extraction took $2 \mathrm{~h}$ after boiling had started. The essential oil was maintained in an amber glass recipient well closed, weighted and kept at $-20^{\circ} \mathrm{C}$.

\section{Chemical analysis of compounds from essential oil}

The EOLC was analyzed by means of GC-MS (QP5000 - Shimadzu). The chromatography apparatus was equipped of capillary column ZB-5mM, Helium as carrier $(32 \mathrm{cM} / \mathrm{s})$; injector temperature was $260{ }^{\circ} \mathrm{C}$; temperature programmed $60-240{ }^{\circ} \mathrm{C}\left(2{ }^{\circ} \mathrm{C} / \mathrm{min}\right)$; mass spectrum of $70 \mathrm{eV}$. The components of the essential oil were identified based on the basis of their retention indices. The confirmation of its components was done by comparison of their mass spectra with published spectra (Adams, 2001) and those of reference compound from the library of National Institute of Standard and Technology (NIST) database.

\section{Leishmanicidal assays}

Promastigote forms of Leishmania amazonensis (MHOM/Br/75/Josefa isolated from patient with diffuse cutaneous form) were cultured in Warren's medium (brain heart infusion, Himédia/Mumbai, Índia, hemin and folic acid) and Leishmania chagasi promastigote forms (MHOM/Br/74/PP75 isolated from patient with visceral form) were cultured in 199 medium, both supplemented with $10 \%$ fetal bovine serum at $24{ }^{\circ} \mathrm{C}$. The antileishmanial activity was determinated by colorimetric 3-(4,5dimethylthiazol-2-yl)-2,5-diphenyl-tetrazolium bromide (MTT) method based on tetrazolium salt reduction by mitochondrial dehydrogenases (Mossman, 1983). Log phase promastigotes of two Leishmania species, were seeded in 96-well tissue culture plates $\left(2.0 \times 10^{6}\right.$ cels $/ \mathrm{mL}$ for $L$. amazonensis and $3.0 \times 10^{6}$ cels $/ \mathrm{mL}$ for $L$. chagasi). After $1 \mathrm{~h}$ at $24^{\circ} \mathrm{C}$, the parasites were exposed to increasing dillution of EOLC previously diluted with dimethylsulfoxide (DMSO). The EOLC concentrations were obtained by performing serial dilutions $(1: 2 \mathrm{v} / \mathrm{v})$ from $250 \mu \mathrm{g} / \mathrm{mL}$ to $3.91 \mu \mathrm{g} / \mathrm{mL}$ and from $25 \mu \mathrm{g} / \mathrm{mL}$ to $0.05 \mu \mathrm{g} /$ $\mathrm{mL}$. Each concentration was performed in triplicate. Two independent experiments were performed for each species during $72 \mathrm{~h}$ incubation period. The DMSO concentration in wells was not higher than $0.01 \%$. Controls with DMSO and without EOLC were also performed. The readouts were done using a spectrophotometer (Spectramax 190, Molecular Devices) at $570 \mathrm{~nm}$ and the results were expressed as the concentrations inhibiting parasite growth by $50 \%$ (IC50) after $72 \mathrm{~h}$ incubation period. Amphotericin $\mathrm{B}$ was used as the reference standard drug with a $72 \mathrm{~h}$ incubation period. For data analysis: IC50 values were obtained using the adjusted straight lines in figure 1.

In vitro and in vivo toxic assays

\section{Macrophages}

To evaluate the in vitro cytotoxic effect of EOLC on live cells, macrophages from J774A.1 lineage was used. $10^{6}$ cells/well were added in 96 well plates which were kept for $24 \mathrm{~h}$ in $\mathrm{CO}_{2} 5 \%$ incubator at $37^{\circ} \mathrm{C}$, allowing macrophages adherence. After $24 \mathrm{~h}$, each well was washed with PBS and received RPMI-1640 medium with $10 \%$ of fetal bovine serum. Then, the solutions of 
essential oil containing DMSO and the DMSO solutions which were at the same concentrations used in the Leishmanicidal assays, were added to the wells. The plates were kept in the $\mathrm{CO}_{2} 5 \%$, incubator at $37{ }^{\circ} \mathrm{C}$, for 48 or $72 \mathrm{~h}$. Macrophages viability was determined by the MTT assay, as described above, and was confirmed by comparison of its morphology with the cells from the control group via light microscopy. Dose response curves were plotted taking the values expressed as percentage of control optical density and CC50 values (50\% cytotoxicity concentration) were obtained using GraFit Version 5 software (Erithacus Software Ltd., Horley, U.K).

\section{Hatching of brine shrimp larvae}

Artificial saline water was used to permit the hatch of brine shrimp larvae. It was prepared dissolving mineral enriched sea salt (SERA, Germany) in de-ionized water at a concentration of $35 \mathrm{~g} / \mathrm{L}$. Brine shrimp eggs (Tropfish) were sprinkled into a $100 \mathrm{~mL}$ becker of containing 50 $\mathrm{mL}$ of saline solution and were kept during $48 \mathrm{~h}$ under constant oxygenate at room temperature $\left(26{ }^{\circ} \mathrm{C}\right)$. After this period, the eggs had hatched and second instar nauplii (larvae) were observed to be swimming near the light source. Sample preparation: EOLC was diluted in DMSO and saline solution water at a standard concentration of $20 \mathrm{mg} / \mathrm{mL}$ using shaking. The final percentage of DMSO in standard solution was $1.0 \%$. Brine shrimp test using Artemia salina: triplicates for each concentration of EOLC and controls were used. Three first assay $5 \mathrm{~mL}$ tubes were pre-filled with $1250 \mu \mathrm{L}$ of saline solution. Next, $2750 \mu \mathrm{L}$ of essential oil solution were added to the three first tubes. Another set of tubes received $2000 \mu \mathrm{L}$ of saline solution. A serial dilution was performed transferring $2000.0 \mu \mathrm{L}$ of solution from three first tubes (initial concentration = $1.375 \mathrm{mg} / \mathrm{mL}$ ) to following tubes. The final concentration of the last tubes was $0.001328 \mathrm{mg} / \mathrm{mL}$ ). Finally, ten second instar larvae in a minimum of saline solution were added to all tubes. Positive and negative controls were performed using artificial saline water and timol. Timol and DMSO (the vehicle) were tested at the same concentrations used for EOLC. The tubes were kept at room temperature and mortality was evaluated after 24 h (Fabri et al., 2011). Statistical analysis to adjust death percentage was performed using Wilcoxon and Lichfield method through Probit analysis (Finney, 1971), permitting the determination of LC50 (50\% lethal concentration of nauplii).

\section{In vivo toxicity test with $B A L B / c$ mice}

In order to evaluate the in vivo toxicity of EOLC ten BALB/c mice from Centro de Biologia da Reprodução, Universidade Federal de Juiz de Fora, were used. This methodology to investigate the acute toxicity is in accordance to the Animal Ethic Committee (AEC Number 063/2007-CCEA), which uses the principle of "3Rs" (NC3Rs, 2012) by the reduced number of animals used in experiments (Ministério da Saúde, 2004). The animals weightening approximately $28 \mathrm{~g}$ were separated in two groups of five animals each (test group: EOLC and control group: DMSO). During the first day, and only during that day, the test group received $0.1 \mathrm{~mL}$ of EOLC solution in DMSO and sterile $\mathrm{H}_{2} \mathrm{O}$ with essential oil concentration of $84 \mathrm{mg} / \mathrm{mL}$. This corresponds to a mean dose of $300 \mathrm{mg} / \mathrm{kg}$. The control group received the same amount of DMSO solution at $0.1 \%$ in sterile $\mathrm{H}_{2} \mathrm{O}$, which corresponds to the same amount of DMSO administrated to the test group. The solutions were administered by gavage. Following a protocol suggested by Peters (1948), during four consecutive days the body masses of the animals were measured and analyzed using ANOVA test statistics.

\section{Results and Discussion}

The EOLC yielded $0.33 \%(\mathrm{w} / \mathrm{w})$ providing approximately $100 \mu \mathrm{L}$ of essential oil from each extraction using $300 \mathrm{~g}$ of dried leaves. This value is in total agreement with the yield value of $0.2 \%(\mathrm{w} / \mathrm{w})$ reported in the recent work of Chowdhury et al. (2007). About the composition of EOLC, thirty constituents representing $86.79 \%$ of the EOLC were identified. The major constituents were: germacrene-D $(24.90 \%),(E)$ cariophylene $(14.31 \%), \quad(E, E)$-farnesene $\quad(11.58 \%)$, $\alpha$-cariophylene $(8.34 \%), \quad(Z, E)$ - $\alpha$-farnesene $\quad(5.03 \%)$ (E)- $\beta$-farnesene $(4.04 \%), \beta$-sesquiphelandrene $(3.35 \%)$, $\beta$-elemene $(2.27 \%), 2$-pentadecin-1-ol (1.38\%) and $(E)$ diidro-apofarnesol $(1.13 \%)$. The chemical compounds of the EOLC evaluated by comparison of identified peaks by GC/MS analysis are shown in the Table 1.

The constitution of EOLC as reported in literature varies greatly depending on the localization and period of collection. Da Silva et al. (1999) found large variations of EOLC composition within samples from several places in the Amazon region of North Brazil.

The germacrene-D was present in some EOLC analyzed (Sundufu \& Shoushan, 2003; Da Silva et al., 1999; Khan et al., 2002) and the cariophylene groups were observed to be the only versatile components present in every EOLC analyzed by different authors (Ngassoum et al., 1999; Sefidkon, 2002; Rana, 2005), which is confirmed by the present work.

On the other hand our data shows, for the very first time that the farnesene derivatives to be representing more than $20 \%$ of the EOLC $(E, E)$-farnesene $(11.58 \%)$, $(Z, E)$ - $\alpha$-farnesene $5.03 \% \quad(E)$ - $\beta$-farnesene $\quad(4.04 \% \quad(E)$ diidro-apofarnesol (1.13\%), (Z)- $\beta$-farnesene $(0.49 \%)$, in contrast with other works, which had shown small amounts of these derivates, or only one kind of them in an 
EOLC (Benites et al., 2009; Padalia et al., 2010).

Table 1. Chemical constituents of essential oil from leaves of Lantana camara from Brazil.

\begin{tabular}{|c|c|c|c|}
\hline Peak number & Constituents & Kovats Index & $\%$ \\
\hline 1 & $\alpha$-pinene & 938 & 0.23 \\
\hline 2 & $\beta$-pinene & 978 & 0.25 \\
\hline 3 & mircene & 982 & 0.27 \\
\hline 4 & heptan-2,2,4,6,6-pentametil & 989 & 0.25 \\
\hline 5 & linalool & 1035 & 0.67 \\
\hline 6 & $\alpha$-terpineol & 1202 & 0.73 \\
\hline 7 & $\begin{array}{l}\text { 1,5-heptadiene, } 2,5- \\
\text { dimethyl-3-methylene }\end{array}$ & 1332 & 0.39 \\
\hline 8 & $\begin{array}{l}\text { 1,5-heptadiene, } 2,5- \\
\text { dimethyl-3-methylene }\end{array}$ & 1336 & 0.64 \\
\hline 9 & longiciclene & 1374 & 0.39 \\
\hline 10 & $\beta$-cubebene & 1387 & 0.41 \\
\hline 11 & $\beta$-elemene & 1390 & 2.27 \\
\hline 12 & (Z)-cariophylene & 1405 & 0.83 \\
\hline 13 & (E)-cariophylene & 1420 & 14.31 \\
\hline 14 & cis-thujopsene & 1425 & 0.47 \\
\hline 15 & $\gamma$-elemene & 1431 & 0.48 \\
\hline 16 & (Z)- $\beta$-farnesene & 1444 & 0.49 \\
\hline 17 & $\alpha$-cariophylene & 1456 & 8.34 \\
\hline 18 & $(E)-\beta$-farnesene & 1459 & 4.04 \\
\hline 19 & germacrene-D & 1484 & 24.90 \\
\hline 20 & Not identified & 1487 & 5.78 \\
\hline 21 & $(Z, E)$ - $\alpha$-farnesene & 1496 & 5.03 \\
\hline 22 & $(E, E)$-farnesene & 1500 & 11.58 \\
\hline 23 & $(Z)$ - $\gamma$-bisabolene & 1510 & 0.42 \\
\hline 24 & $\beta$-sesquiphelandrene & 1514 & 3.35 \\
\hline 25 & (E)- $\gamma$-bisabolene & 1520 & 0.78 \\
\hline 26 & spatulenol & 1526 & 0.45 \\
\hline 27 & 2-pentadecin-1-ol & 1558 & 1.38 \\
\hline 28 & davanone & 1579 & 0.77 \\
\hline 29 & (E)-diidro-apofarnesol & 1581 & 1.13 \\
\hline 30 & eudesmol & 1610 & 0.89 \\
\hline 31 & diidromircene, 1,6-diol-Z & 1620 & 0.65 \\
\hline
\end{tabular}

The potential of EOLC against promastigote forms of L. chagasi and L. amazonensis was evaluated in vitro. The toxic aspects of the EOLC were analyzed through the in vitro Brine shrimp test, as well as by the macrophage culture and measuring the masses of BALB/c mice that received EOLC or DMSO solution. The data obtained from EOLC bioassays on promastigote forms of Leishmania revealed a growth inhibition activity of EOLC at low concentrations for the both species of Leishmania sp used in this study, Figure 1.

It is worth to highlight that the EOLC was able to inhibit $100 \%$ L. amazonensis proliferation with concentrations above $3 \mu \mathrm{g} / \mathrm{mL}$. For L. chagasi an inhibition of about $90 \%$ was found with a concentration of $250 \mu \mathrm{g} / \mathrm{mL}$. Extrapolating the straight line of $L$. chagasi data of Figure 1 one may estimate that total inhibition would be obtained with $1 \mathrm{mg} / \mathrm{mL}$ of the EOLC. Below the saturation values, $3 \mu \mathrm{g} / \mathrm{mL}$ and 1 $\mathrm{mg} / \mathrm{mL}$, the inhibition shows a smooth increase with the logarithm of concentration, which permit the determination of IC50 values (Table 2).

The species L. amazonensis was found to be much more susceptible to the EOLC than the L. chagasi, which can be noted from the IC50 values ( $L$. amazonensis with $0.25 \mu \mathrm{g} / \mathrm{mL}$ and $L$. chagasi with $18 \mu \mathrm{g} / \mathrm{mL}$ ). The lower susceptibility of $L$. chagasi is frequently found also with respect to other drugs (Morais-Teixeira et al., 2008; Braga et al., 2007) including the standard drug Amphotericin B (Table 2).

Table 2. Effect of essential oil of Lantana camara on promastigote forms from Leishmania observed in $72 \mathrm{~h}$ culture period.

\begin{tabular}{lcc}
\hline \multicolumn{1}{c}{ Sample } & $\begin{array}{c}\text { L. amazonensis } \\
\text { IC50 }(\mu \mathrm{g} / \mathrm{mL}) \pm \mathrm{SD}\end{array}$ & $\begin{array}{c}\text { L. chagasi } \\
\text { IC50 }(\mu \mathrm{g} / \mathrm{mL}) \pm \mathrm{SD}\end{array}$ \\
\hline EOLC & $0.25 \pm 0.08$ & $18 \pm 4$ \\
Amphotericin B & $0.90 \pm 0.05$ & $1.91 \pm 0.02$ \\
\hline
\end{tabular}

The mechanism of action by which EOLC inhibits the parasite growth is still unknown, however some authors (Wink, 2008; Cabral et al., 2009; Laouer et al., 2009) have shown the biological activity of the major compounds present in this EOLC against other eukaryotes parasites and prokaryote microorganisms, which are distant from Leishmania genus, as punctuated before, this work is the first one that demonstrates the activity of EOLC on promastigote culture of Leishmania, so it is relevant to consider some previous studies which enables the construction of few hypothesis to contribute for explanation of EOLC activity on this protozoa culture.

According to Kasali et al. (2004) germacrene-D was able to inhibit the growth of some bacteria and fungi during the in vitro assays. The presence of germacrene-D in EOLC composition used in Leishmania assays developed in the present work, could be considered as a responsible by the inhibitory growth effect on promastigote culture. This hypothesis is based on the Amphotericin B activity, which is able to act as an antifungal and an antileishmanial drug.

For the first time, farnesene derivatives $(E)$ diidro-apofarnesol, $\quad(E)$ - $\beta$-farnesene, $\quad(Z)$ - $\beta$-farnesene, $(E, E)$-farnesene, $(Z, E)$ - $\alpha$-farnesene) were found as one of the major compounds groups representing $22.27 \%$ of the total percentage in the EOLC used in this study. The real role of farnesene derivatives on the growth of promastigote forms of Leishmania is still unclear and 
needs further studies, although it is pertinent to notice that farnesol, a derivative alcohol from farnesenes, was relevant in increasing susceptibility of the Staphylococcus aureus culture (Kuroda et al., 2007) and against the fungi Candida albicans in culture (Sato et al., 2004). Consequently the action of farnesene derivatives on Leishmania culture, could be related with the enhance of promastigote susceptibility as it was cited in the case of other microorganisms, independent of the evolutionary distance, once there is a drug example with this possible action, which was also cited, the Amphotericin B.

Once the cariophylene derivatives present in EOLC of this work did not inhibit growth of other protozoan species in culture, such as the amoebic and giardial ones according Calzada et al. (2001), it might be that this molecule doesn't have any inhibitory action on promastigote forms growth. Another possible suggestion as to the active components of the EOLC may be obtained from studies of other active essential oils on Leishmania. Costa et al. (2009a) identified the compounds of essential oil from leaves of Annona foetida (Annonaceae) and tested antileishmanial action with promastigotes of Lamazonensis (IC50 $16 \mu \mathrm{g} / \mathrm{mL}$ ) and L. chagasi (IC50 $27 \mu \mathrm{g} / \mathrm{mL}$ ). The substances $\beta$-cubebene, $\beta$-elemene, $(E)$-cariophylene, $(E)$ $\gamma$-bisabolene and spathulenol are present in both essential oils and the active components may be from this group.

The Brine shrimp used to evaluate the toxicity of EOLC revealed on lethality assay a LC50 $12 \pm 3 \mu \mathrm{g} /$ $\mathrm{mL}$, and it is still in accordance with Costa et al. (2009b), that reported a LC50 value of $14 \mu \mathrm{g} / \mathrm{mL}$ for the same EOLC. The essential oil activity on Artemia salina revealed a 48-fold higher LC50 than the IC50 from $L$. amazonensis, and even the saturating concentration of $3 \mu \mathrm{g} / \mathrm{mL}$, which inhibits L. amazonensis completely, is still four times smaller than LC50. This is an interesting relation between inhibitory doses of promastigote growth and a multi-cellular organism. However, its toxicity has to be considered as extremely high, since its LC50 is significantly lower than $1000 \mu \mathrm{g} / \mathrm{mL}$, the pattern limit of toxicity (Costa et al., 2009).

Unfortunately, in the case of L. chagasi the results are less promising. The fact that $L$. chagasi is more resistant than L. amazonensis is known in literature. Braga et al. (2007) found a IC50 value of the methanol extract of leaves from $L$. camara of $14 \mu \mathrm{g} / \mathrm{mL}$ for $L$. amazonensis and of $250 \mu \mathrm{g} / \mathrm{mL}$ for L. chagasi (Braga et al., 2007). Even though the IC50 (L. chagasi) of the EOLC is lower than that of vegetal extracts of twenty different species of plants tested against the same strain of promastigote forms used in the present work (Braga et al., 2007). A similar situation was found with respect to cytotoxicity of EOLC. The investigation about the cytotoxicity of EOLC was realized with the macrophage culture and it revealed low values of CC50 for both different culture times evaluated ( $48 \mathrm{~h}$, $6.2 \mu \mathrm{g} / \mathrm{mL}$ and $72 \mathrm{~h}, 4.7 \mu \mathrm{g} / \mathrm{mL}$ ). These values are almost nineteen times bigger than the IC50 of L. amazonensis and they are still bigger than the saturating concentration of $3 \mu \mathrm{g} / \mathrm{mL}$, which inhibits L. amazonensis completely. Nevertheless, the values $48 \mathrm{~h}, 6.2 \mu \mathrm{g} / \mathrm{mL}$ and $72 \mathrm{~h}, 4.7 \mu \mathrm{g} /$ $\mathrm{mL}$ represent the presence of a high cytotoxicity (Costa et al., 2009b). In the case of L. chagasi the comparison of IC50 and CC50 is less favorable. But this toxic effect is not due to hepatotoxic triterpenes, once these compounds are not present in the EOLC composition. Consequently, new studies are necessary to explain the high toxicity exhibited by the EOLC used in the present study.

According to Santos et al. (2008) the toxic effects on bovines occur approximately $2 \mathrm{~h}$ after the ingestion of some parts of the plant and after 24-48h the animals reveal an appetite inhibition leading to reduction of body mass. In the present study, $300 \mathrm{mg} / \mathrm{mL}$ per $\mathrm{kg}$ of body mass of EOLC were administered to BALB/c mice and did not reveal significant alterations related to their masses through the 4-day analysis according to the ANOVA test ( $p$ value 0.6472 ). Since results of toxicity test in vivo with BALB/c mice did not reveal a significant difference in masses of mice $(p>0.05)$, it suggests absence of acute manifestation of toxicity in mice caused by EOLC.

According to Sanchez-Brunete et al. (2004), Amphotericin B caused behavior alterations and death in hamsters that received it at doses that ranged from 10 to $20 \mathrm{mg} / \mathrm{mL}$ per $\mathrm{kg}$ of body weight along a $48 \mathrm{~h}$ period. Comparing the doses used in this study to those used in the mentioned one, despite different species, it is possible to suggest a remarkably higher toxicity of Amphotericin B than EOLC, which revealed significant inhibitory activity of promastigote proliferation in vitro.

Additionally, it is possible to suggest that its toxic effect observed in brine shrimp test and mammals cells in vitro is not related to the presence of germacren-D, because it was evaluated in the same models and no toxic effect was observed according to Biavatti et al. (2001).

Moreover, regardless of the high toxicity shown for oil through the brine shrimp test and macrophages, it is important to consider that the amphotericin B, second-line drug for the treatment of cutaneous mucosa leishmaniasis, also has high toxicity to humans, even causing kidney failure (Lopez-Berestein et al., 1987; 1989). However, according to Sampaio \& Marsden (1997) the association of liposomes with amphotericin B increases its tolerability by patients because this association interacts directly with the parasite ergosterol and reacts less with the cholesterol of the host. And it also enhances the ability of macrophage to phagocyte the parasite. Similar association techniques may also work with EOLC.

Thus, our work has confirmed the diversity of EOLC composition, once, for the first time, the farnesene derivates were identified. In addition, the presence of potential activity of EOLC against promastigote forms was revealed. Despite the high toxic results obtained 
for the macrophage culture and brine shrimp test, the absence of its toxicity on BALB/c mice model encourage investment in new researches. In conclusion, the results obtained suggesting that the EOLC may be a potential source of medicine for leishmaniasis treatment. Further studies are necessary to determine the active components in the EOLC and whether the leishmanicidal and citotoxic components are distinct chemical species.

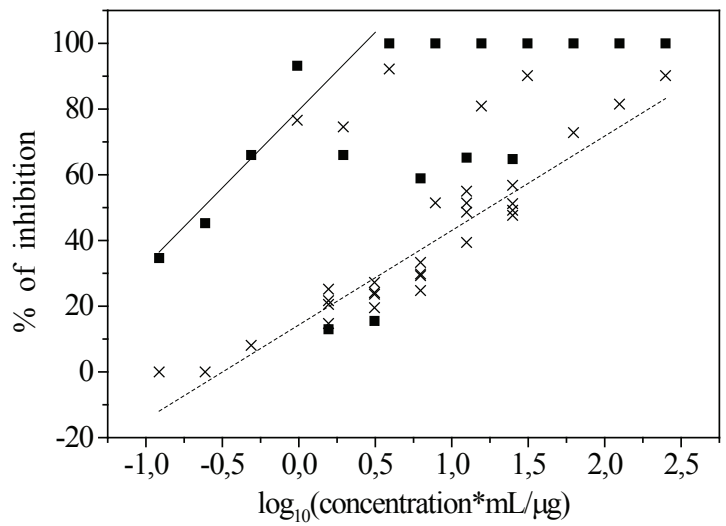

Figure 1. Effect of essential oil from leaves of Lantana camara on promastigote culture of L. amazonensis (squares) and L. chagasi (crosses). The straight lines indicate the general behaviors up to the saturation concentrations. They were obtained by fitting reduced sets of data points that ignored dubious results and the saturation region.

\section{Acknowledgements}

We thank the Fundação de Amparo a Pesquisa e Extensão de Minas Gerais for financial support (Process nr. CEX - APQ-00246-10). We thank Maria Cristina de Holanda Pereira Lima (NPPN - UFRJ) for the technical support with the essential oil analysis with GC-MS.

\section{References}

Adams RP 2001: Identification of essential oil components by gas chromatography quadrupole mass spectroscopy: Allured Publishing Corporation: Illinois.

Benites J, Moiteiro C, Miguel G, Rojo L, Lopez J, Venancio F, Ramalho L, Feio S, Dandlen S, Casanova H 2009. Composition and biological activity of the essential oil of Peruvian Lantana camara. J Chil Chem Soc 54: 379384.

Bezerra JL, Costa GC, Lopes TC, Carvalho ICDS, Patrício FJ, Sousa SM, Amaral FMM, Rebelo JMM, Guerra RNM, Ribeiro MNS, Nascimento FRF 2006. Avaliação da atividade leishmanicida in vitro de plantas medicinais. Rev Bras Farmacogn 16(Supl.): 631-637.

Biavatti MW, Vieira PC, da Silva MFGF, Fernandes JB, Albuquerque S, Magalhães CMI, Pagnocca FC 2001. Chemistry and bioactivity of Raulinoa echinata Cowan, an endemic Brazilian Rutaceae species. Phytomedicine 8: 121-124.

Braga FG, Bouzada MLM, Fabri RL, Matos MO, Moreira FO, Scio E, Coimbra ES 2007 Antileishmanial and antifungal activity of plants used in tradicional medicine in Brazil. J Ethnopharmacol 111: 396-402.

Cabral C, Gonçalves MJ, Cavaleiro C, Sales F, Boyom F, Salgueiro L 2009. Composition and anti-fungal activity of the essential oil from Cameroonian Vitex rivularis Gürke. Nat Prod Res 23: 1478-1484.

Calzada F, Cedillo-Rivera R, Mata R 2001. Antiprotozoal activity of the constituents of Conyza filaginoides. J Nat Prod 64: 671-673.

Cammerer SB, Jimenez C, Jones S, Gros L, Lorente SO, Rodrigues C, Rodrigues JCF, Caldera A, Perez LMR, da Souza W, Kaiser M, Brun R, Urbina JA, Pacanowska DG, Gilbert IH 2007. Quinuclidine derivatives as potential antiparasitics. Antimicrob Agents Chemother 51: 4049-4061.

Chowdhury JU, Nandi N C, Bhuiyan MDNI 2007. Chemical composition of leaf essential oil of Lantana camara 1. from Bangladesh. Bangladesh J Bot 36: 193-194.

Clem A 2010. A current perspective on Leishmaniasis. J Glob Infect Dis 2: 124-126.

Costa EV, Pinheiro MLB, Silva JRA, Maia BHLNS, Duarte MCT, Amaral ACF, Machado GMC, Leon LL 2009a. Antimicrobial and antileishmanial activity of essential oil from the leaves of Annona foetida (Annonaceae). Quim Nova 32: 78-81.

Costa JGM da, Sousa EO de, Rodrigues FFG, Lima SG de, Braz-Filho R 2009b. Chemical composition, evaluation of antibacterial activity and toxicity of the essential oils from Lantana camara L. and Lantana sp. Rev Bras Farmacogn 19: 710-714.

Cruz AK, de Toledo JS, Falade M, Terrao MC, Kamchonwongpaisan S, Kyle DE, Uthaipibull C March 2009. Current treatment and drug discovery against Leishmania spp. and Plasmodium spp.: a review. Curr Drug Targ 10: 178-192.

Da Silva MHL, Andrade EHA, Zoghbi MB, Luz AIR, da Silva JD, Maia JGS 1999. The essential oils of Lantana camara L. occurring in North Brazil. Flavour Fragr $J$ 14: 208-210.

Deena MJ, Thoppil JE 2000. Antimicrobial activity of the essential oil of Lantana camara. Fitoterapia 71: 453455.

Fabri RL, Nogueira MS, Moreira JR, Bouzada MLM, Scio E 2011. Identification of antioxidant and antimicrobial compounds of Lippia species by bioautography. J Med Food 7-8: 840-846.

Finney DJ 1971. Probit analysis, $3^{\text {a }}$ ed. University Press, Cambridge.

Ghisalberti EL 2000. Lantana camara Linn (Rev.). Fitoterapia 71: 467-485.

Kasali AA, Ekundayo O, Paul C, Koenig W, Eshilokun AO, 
Yadua P 2004. Essential oil of Lantana camara L. var. aculeate from Nigeria. J Essent Oil Res 16: 588-593.

Khan M, Srivastva SK, Syamisunder KV, Singh M, Naquvi AA 2002. Chemical composition of leaves and flower essential oil of Lantana camara from India. Flav Fragr J 17: 75-77.

Kuroda M, Nagasaki S, Ohta T 2007. Sesquiterpene farnesol inhibits recycling of the C55 lipid carrier of the murein monomer precursor contributing to increased susceptibility to $\beta$-lactams in methicillin-resistant Staphylococcus aureus. J Antimicr Chemother 59: 425432.

Laouer H, Yabrir B, Djeridane A, Yousfi M, Beldovini N, Lamamra M 2009. Composition, antioxidant and antimicrobial activities of the essential oil of Marrubium deserti. Nat Prod Commun 4: 1133-1138.

Lopez-Berestein G, Bodey GP, Frankel LS, Mehta K 1987. Treatment of hepatosplenic candidiasis with liposomalamphotericin B. J Clin Oncol 5: 310-317.

Lopez-Berestein G, Bodey GP, Fainstein V, Keating M, Frankel LS, Zelluf B, Gentry L, Mehta K 1989. Treatment of systemic fungal infections with liposomal amphotericin B. Arch Intern Med 149: 2533-2536.

Ministério da Saúde, 2004. Conselho Nacional de Saúde. Comissão Nacional de Ética em Pesquisa. Manual Operacional para Comitês de Ética em Pesquisa. Brasília: Ministério da Saúde, p. 124.

Mishra J, Saxena A, Singh S 2007. Chemotherapy of leishmaniasis: past and future. Curr Med Chem 14: 1153-1169.

Morais-Teixeira E, Carvalho AS, Costa JCS, Duarte SL, Mendonça JS, Boechat N, Rabello A 2008. In vitro and in vivo activity of meglumine antimoniate produced at Farmanguinhos-Fiocruz, Brazil, against Leishmania (Leishmania) amazonensis, $L$ (L.) chagasi and $L$ (Viannia) braziliensis Mem I Oswaldo Cruz 103: 358362.

Mossman T 1983. Rapid colorimetric assay for cellular growth and survival: applications to proliferation and cytotoxicity assay. J Immunol Methods 16: 55-63.

Murray HW, Berman JD, Davies CR, Saraiva NG 2005. Advances in leishmaniasis. Lancet 366: 1561-1577.

NC3Rs 2012. National Center for the Replacement Refinement and Reduction of Animals in Research. Avaiable at: http://www.nc3rs.org.uk.

Ngassoum MB, Yonkeu S, Jirovetz L, Buchbauer G, Schmaus G, Hammerschmidt FJ 1999. Chemical composition of essential oils of Lantana camara leaves and flowers from Cameroon and Madagascar. Flav Fragr J 14: 245-250.

Padalia C, Verma RS, Sundaresan V 2010. Volatile constituents of three invasive weeds of Himalayan region Rajendra. Rec Nat Prod 4: 109-114.

Peters W 1948. Drug resistance in Plasmodium berghei Vincke and Lips. Exp Parasitol 1965: 97-102.
Raju A 2000. Wild plants of Indian sub-continent and their economic uses. CBS Pub. \& Distribution, New Delhi p. 65.

Rana VS, Prasas D, Amaro B 2005. Chemical composition of the leaf oil of Lantana camara. J. Ess Oil Res 17: 198200.

Salem MM, Werbovetz KA 2006. Natural products from plants as drug candidates and lead compounds against leishmaniasis and trypanosomiasis. Curr Med Chem 13: 2571-2598.

Sampaio RNR, Marsden PD 1997. Tratamento da forma mucosa de leishmaniose sem resposta a glucantime, com anfotericina B liposomal. Rev Soc Bras Med Trop 2: 125-128.

Sanchez-Brunete MA, Dea S, Bola F, Alunda M, Raposo R, Mendez MT, Torrado-Santiago S, Torrado JJ 2004 Treatment of experimental visceral Leishmaniasis with Amphotericin B in stable albumin microspheres. Antimicr Agents Chemother 48: 3246-3252.

Santos JCA, Riet-Correa F, Simoões SVD, Barros CSL 2008. Patogênese, sinais clínicos e patologia das doenças causadas por plantas hepatotóxicas em ruminantes e eqüinos no Brasil. Pesq Vet Bras 28: 1-14.

Sato T, Watanabe T, Mikami T, Matsumoto T 2004. Farnesol, a morphogenetic autoregulatory substance in the dimorphic fungus Candida albicans, inhibits hyphae growth through suppression of a mitogen-activated protein kinase cascade. Biol Pharm Bull 27: 751-752.

Sefidkon F 2002. Essential oil of Lantana camara L occurring in Iran. Flavour Fragr J 17: 78-80.

Sharma OP, Sharma S, Pattabhi Pattabhi V, Mahato SB, Sharma PD 2007. A review of the hepatotoxic plant Lantana camara. Crit Rev Toxicol 37: 313-52.

Sundufu AJ, Shoushan H 2003. Chemical composition of the essential oils of Lantana camara L. occurring in south China. Flav Fragr J 19: 229-232.

Tokarnia CH, Armién AG, De Barros SS, Peixoto PV, Döbereiner J 1999. Estudos complementares sobre a toxidez de Lantana camara (Verbenaceae) em bovinos. Pesq Vet Bras 19: 128-132.

Wink M 2008. Evolutionary advantage and molecular modes of action of multicomponent mixtures used in phytomedicine. Curr Drug Metab 9: 996-1009.

WHO 2010. Leishmaniasis magnitude of the problem. Available at: http://www.who.int/leishmaniasis/burden/magnitude/ burden_magnitude/en/print.html.

\section{*Correspondence}

Rachel R. P. Machado

FCMS/SUPREMA

BR-040, km 796, Bairro Salvaterra, 36045-410 Juiz de ForaMG, Brazil

rachel.machado@suprema.edu.br

Tel: +553221015002 